\title{
ARTÍCULOS ARBITRADOS \\ PROCESOS DE CONSTRUCCIÓN DE CIUDAD Y VIVIENDA INFORMAL. EL CASO DE LAS BARRIADAS INFORMALES DE LOS CERROS ORIENTALES DE BOGOTÁ, COLOMBIA
}

\section{Diana Gómez Navas}

Licenciada en Ciencias Sociales de la Universidad Distrital Francisco José de Caldas, magíster en Ciencia Política de la Universidad de Los Andes. Profesora-investigadora de la Facultad de Ciencias y Educación de la Universidad Distrital Francisco José de Caldas, Bogotá, Colombia.dmgomezn@udistrital.edu.co.

\section{Adrián Serna Dimas}

Antropólogo de la Universidad Nacional de Colombia, magíster en Investigación Social Interdisciplinaria de la Universidad Distrital Francisco José de Caldas y en Sociología de la Universidad Nacional de Colombia. Profesor-investigador de la Facultad de Ciencias y Educación de la Universidad Distrital Francisco José de Caldas, Bogotá, Colombia. aeserna@udistrital.edu.co. 


\section{Resumen}

La urbanización de Bogotá se ha caracterizado por las dificultades de los sectores más pobres para acceder al suelo urbano y a la vivienda. Esta situación adquirió dimensiones dramáticas durante la segunda mitad del siglo XX, cuando los procesos migratorios hacia la ciudad, intensificados por factores como la violencia rural, generaron un crecimiento poblacional desbordado y llevaron a la multiplicación de barriadas informales en las diferentes localidades de la ciudad. Con base en una de las experiencias de asentamientos informales más antiguas de la ciudad, sobre los cerros orientales, el artículo muestra en el curso del tiempo cómo sucedieron las ocupaciones, cuáles fueron las estrategias para su formalización y mejoramiento y los diferentes conflictos que las comunidades barriales tuvieron que sortear para reivindicar su derecho al suelo urbano y a la vivienda frente a diferentes agencias privadas y públicas.

\section{Palabras clave}

Procesos de construcción de ciudad, vivienda informal, formalización y legalización de barrios.

\section{$\underline{\text { Abstract }}$ \\ Development Processes in City Growth and Informal Housing. The Case of Informal Settlements in the Eastern Hills of Bogotá, Colombia}

The urbanization of Bogotá has been characterized by the difficulties that the poorest sectors have had to be able to access urban soil and housing. This situation acquired dramatic dimensions during the second half of the 20th century when migratory processes towards the city were intensified by factors such as rural violence, which generated the excessive growth of population. This situation resulted in the multiplication of informal slums in different city localities. Based on one of the oldest informal settlements on the eastern hillsides, this article shows how they developed over time, what strategies were used for their formalization and improvement and, finally, the different conflicts that neighborhood communities had to resolve to claim their right to urban soil and housing, in opposition to different private and public agencies.

$\underline{\text { Key words }}$ City construction processes, informal housing, neighborhoods formalization and legalization 
Procesos de construcción de ciudad y vivienda informal. El caso de las barriadas informales de los cerros orientales de Bogotá, Colombia

\section{INTRODUCCIÓN}

Hasta comienzos del siglo XX el crecimiento de Bogotá fue sosegado. Sin embargo, el repunte de la economía nacional a comienzos de los años 20 tuvo un impacto significativo en el proceso de urbanización de la ciudad. Por un lado, la ciudad recibió una participación importante de la bonanza cafetera a través de contribuciones tributarias, implementación de nuevas inversiones y negocios y, particularmente, por medio de una serie de obras públicas que empezaron a desarrollarse. Por otro lado, empezó a ser el asiento de una institucionalidad económica y política más prominente, que la convirtió en el eje de las inversiones públicas y privadas, lo que amplió su capacidad industrial y el sector comercial existente. ${ }^{1}$ Todo esto representó un estímulo importante para el proceso de expansión urbana, que adquirió mayor intensidad desde entonces: para 1918 la ciudad tenía alrededor de 144.000 habitantes, para 1928 superaba los 230.000 habitantes, para 1938 llegó a albergar más de 330.000 y para mediados de siglo contaba con más de 620.000 habitantes (AME, 1940; AME, 1960).

Desde entonces quedó expuesta a una dinámica de crecimiento acelerado que trajo consigo o profundizó una serie de problemas, entre ellos, el acceso al suelo y a la vivienda por parte de los sectores más pobres. Si bien desde finales del siglo XIX las administraciones municipales emprendieron procesos de higienización y mejoramiento de algunas barriadas populares, los asentamientos informales o subnormales se fueron extendiendo por los márgenes de la ciudad. ${ }^{2}$ Para la segunda mitad del siglo XX, con el aumento ostensible de la población producto de una desruralización violenta ${ }^{3}$, la ciudad no pudo responder a las demandas de suelo urbano, de habitaciones y de servicios públicos, lo que trajo un incremento del hacinamiento, un aumento en los costos para ocuparla y, obviamente, una expansión de la informalidad habitacional.

Los estudios sobre los procesos de formalización de vivienda o sobre la aparición de barrios informales en Bogotá han hecho énfasis en las historias de las ocupaciones, en su relación con las políticas vigentes de desarrollo urbano, en el papel que han cumplido las agencias públicas y privadas y en la caracterización de los efectos de la formalización en los patrones habitacionales urbanos (ARANGO, 1986; JARAMILLO, 1992; TORRES, IAKIMOVA Y Rincón, 2009; Torres, 2011; CAMARgo y Hurtado, 2012, 2013). Pese a ello, son pocos los estudios que muestran las contradicciones, las tensiones y las negociaciones que se suscitan en el marco de los procesos de formalización urbana entre los ocupantes informales, el Estado y los agentes privados.
1. Sobre los procesos de transformación de la ciudad de Bogotá, véase: Mejía (1999), CASTILLO (2003), CASTRO (2009), ZAMBRANO Y ROBERTO (2007), SERNA Y GOMEZ (2011). 2. Cabe señalar que desde las primeras décadas del siglo XX la ciudad presenció el crecimiento voraz de fenómenos como el hacinamiento y la ausencia de servicios públicos sanitarios para los sectores pobres que se instalaban en ella. Esta situación contribuyó a la proliferación de epidemias y al asentamiento de unos cordones de miseria que fueron objeto de toda suerte de estigmas. Aunque se tomaron algunas medidas por parte de las agencias públicas, estas continuaban siendo tímidas, aisladas y con un fuerte carácter policivo, todo lo cual llevó a que la situación hiciera crisis en 1918, cuando la ciudad se vio afectada por la epidemia de la gripe española. Desde entonces se implementó con un carácter mucho más decidido una serie de politicas de higienización de dichos sectores marginales, muchas de las cuales lograron su desaparición. Sobre las politicas de higiene en Bogotá 
véase: MARTINEZ (1987), COLOON (2005), GutiérRez (2010), RODRIGUEZ (2014).

3. Para los años 60 la ciudad se acercaba al millón de habitantes y hacia mediados de los años 70 ya contaba con cerca de tres millones (AME, 1960; AEB, 1974).
La investigación "Asentamiento, ocupación y derecho a la ciudad. Una historia social de los procesos de construcción de ciudad en la cuenca del río Arzobispo, Bogotá 1885-2000" indagó las contradicciones que se suscitaron entre las aspiraciones del mercado y las actuaciones del Estado en medio de los procesos de construcción de ciudad desde finales del siglo XIX. La perspectiva de la historia social le exigió a la investigación en su conjunto ubicar los contextos en los cuales las dinámicas de los distintos campos sociales supusieron marcos de confrontación a las condiciones y posibilidades de los habitantes urbanos para hacer y hacerse a la ciudad. Para esto la investigación apeló fundamentalmente a fuentes documentales exploradas y analizadas desde sus condiciones históricas de producción, es decir, buscando las circunstancias que estuvieron detrás de diferentes intervenciones e inversiones urbanas, el impacto en las existencias concretas de los pobladores urbanos, las demandas de estos como ciudadanos y las formas de organización y movilización social y política.

En este contexto, la investigación pudo esclarecer las insuficiencias de las políticas de desarrollo urbano emprendidas por la ciudad de cara al problema del acceso a la vivienda para los sectores de escasos recursos; también pudo recuperar algunos de los procesos de construcción de barrios informales con mayor antigüedad en la historia urbana de la ciudad, los conflictos y tensiones que los atravesaron, así como los procesos organizativos y reivindicatorios que emprendieron sus habitantes. Precisamente, el artículo busca poner en evidencia no solo la trayectoria de una política urbana de formalización de barrios de pocos alcances, sino, particularmente, revelar a través de algunos procesos de ocupación y construcción informal de barrios en los cerros orientales de la ciudad la forma como estos llegaron a confrontar tanto las acciones del mercado urbano que privilegiaba los intereses habitacionales de las clases medias y altas como las actuaciones del Estado en materia de planeación y desarrollo urbano.

\section{POLÍTICAS DE FORMALIZACIÓN DE BARRIOS}

La epidemia de gripe española de 1918 puso en evidencia las nefastas condiciones de habitabilidad que soportaban las grandes masas urbanas de una ciudad como Bogotá. Precisamente en esta coyuntura apareció, tal vez, la primera disposición en materia de construcción de vivienda de interés social emitida en el país, la Ley 46 de 1918, que fomentó la construcción de habitaciones higiénicas para la clase obrera. Aunque desde mediados de los años 10 el Concejo Municipal había surtido diferentes disposiciones para paliar los problemas de las barriadas obreras, las medidas se hicieron más consistentes — aunque no 
Procesos de construcción de ciudad y vivienda informal. El caso de las barriadas informales de los cerros orientales de Bogotá, Colombia

necesariamente más aplicables - desde 1918. En este año el Concejo Municipal expidió los acuerdos 37 y 38, que dispusieron la conformación de juntas de habitaciones para los barrios obreros y que ordenaron al Municipio la adquisición de los terrenos sobre los cuales se alzaban las barriadas obreras entre el Paseo de Bolívar y los Altos de San Diego y la destrucción de los ranchos allí asentados (RM, 229-234). Además, con la creación de la Junta de Habitaciones para Obreros, la ciudad respondía a las obligaciones que había dictaminado la Ley 46 de 1918.

Más adelante, por medio del Acuerdo 61 de 1932, la junta fue sustituida por el Instituto de Acción Social (IAS), el cual tuvo dos objetivos fundamentales: promover el acceso a la pequeña propiedad urbana y auspiciar el mejoramiento de barriadas en malas condiciones habitacionales. Sin embargo, estas instituciones continuaron ancladas a la vieja prédica del higienismo y la moralización ${ }^{4}$.

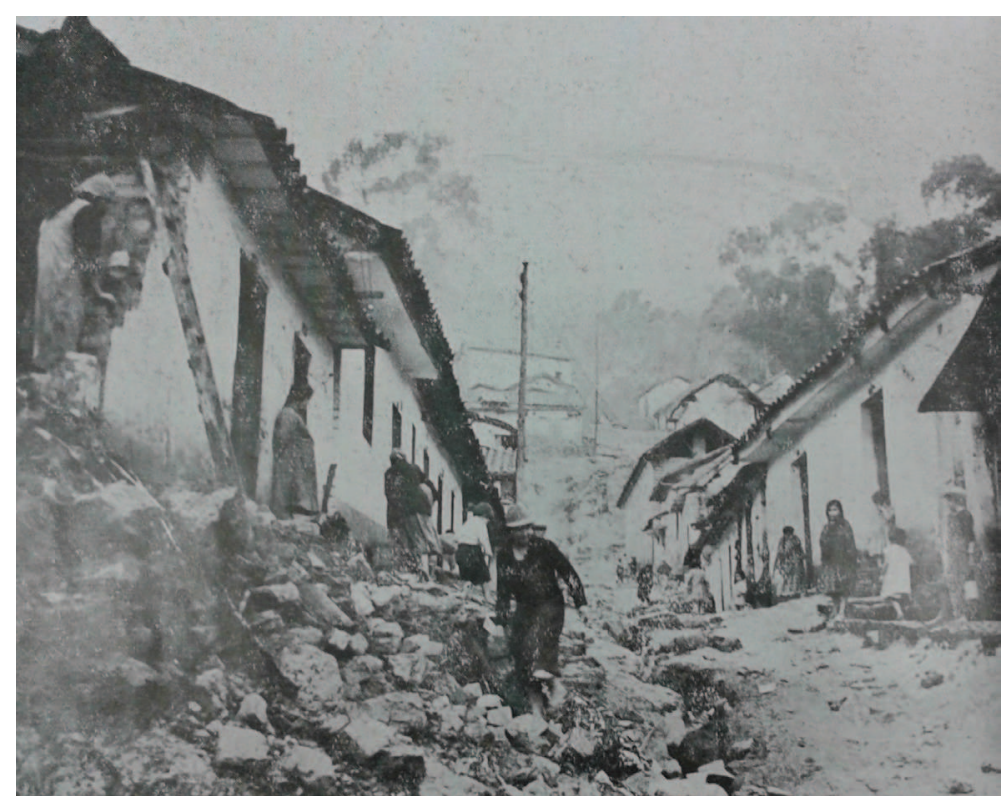

4. Estudios como el de SALDARRIAGA (1995) y CEBALLOS (2008) permiten comprender la manera en que los informes técnicos y las denuncias de instancias y organizaciones médicas frente a las pésimas condiciones de salubridad en las que vivían los llamados sectores obreros en la ciudad favorecieron la construcción de una concepción higienista, que inspiró y sostuvo buena parte de la acción de las agencias públicas en materia de política e intervención urbana dirigida a estos sectores.

Figura 1

Aspecto de una calle del Paseo Bolívar, sobre los cerros orientales, antes de los procesos de higienización que terminaron con estas barriadas informales Fuente: Registro Municipal, Año LVII, Nov.-Dic. de 1937, Nos. 117-120. 


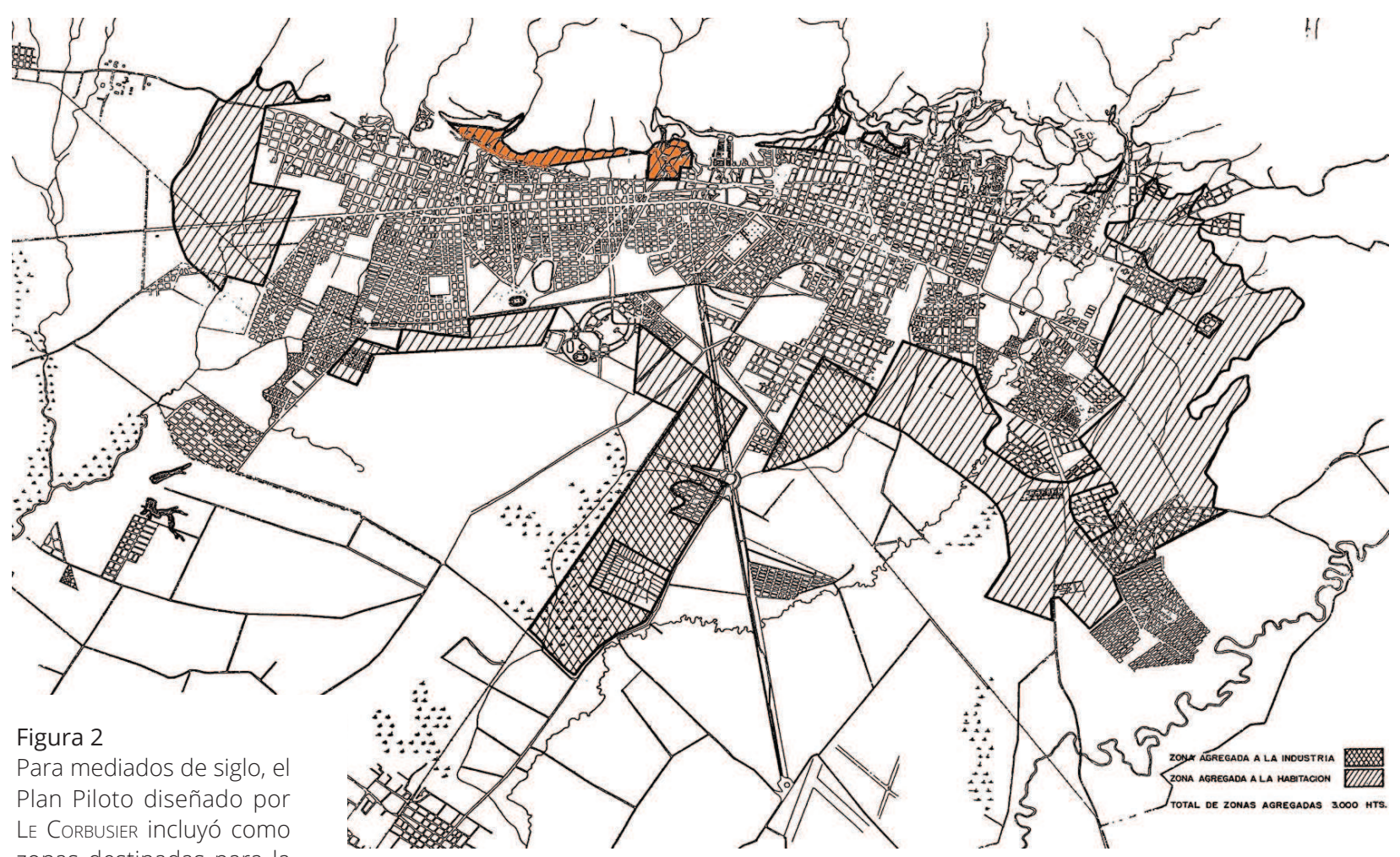

zonas destinadas para la habitación parte de los predios ubicados sobre los cerros orientales de la ciudad, donde ya se ubicaban varias barriadas informales.

Fuente: Registro Municipal, Año LXXI, Nos. 443-441. 
Procesos de construcción de ciudad y vivienda informal. El caso de las barriadas informales de los cerros orientales de Bogotá, Colombia

Para estos momentos la Municipalidad ya había vislumbrado sus limitaciones frente a la regulación del desarrollo urbano, particularmente, porque la ciudad venía siendo objeto de grandes intervenciones públicas y de diferentes proyectos urbanizadores privados que llevaron a que en el año de 1933 se creara el Departamento de Urbanismo (Acuerdo 28 de 1933). El departamento estuvo inicialmente a cargo del urbanista austríaco KARL BRUNNER, quien contribuyó a definir algunas políticas urbanas, pero también participó en el diseño de urbanizaciones tanto de barrios "obreros" como de barrios "residenciales". ${ }^{5}$ El trabajo del departamento buscó hacer del desarrollo urbano un proceso orquestado por disposiciones urbanísticas claras, por la formulación de políticas y de planes que contribuyeran a la idea de un crecimiento ordenado de la ciudad. ${ }^{6}$ Pese a ello, la planeación urbana de la ciudad seguía al vaivén de los grandes proyectos de obras públicas y del apetito voraz de los urbanizadores privados. Así, para emprender el proceso de reconstrucción de la ciudad luego de los sucesos del 9 de abril de 19487, la Municipalidad contrataría al urbanista suizo Le Corbusier para que, al frente de la recién creada Oficina del Plan Regulador de Bogotá (Acuerdo 88 de 1948), construyera un plan para ejecutar una amplia intervención urbana en el centro de la ciudad (AriAs, 2008).

No obstante, para mediados del siglo, la ciudad continuaba con un crecimiento de barrios informales en las peores condiciones, lo que llevó a que el Acuerdo 27 de 1966 dispusiera la creación del Fondo de Sustitución de Tugurios, orientado a crear planes para resolver el problema de la vivienda de invasión. Sin embargo, el fondo resultó insuficiente, tanto más cuanto la urbanización adquirió proporciones dramáticas en los años siguientes, que condujeron a que el Municipio se englobara como una nueva entidad: el Distrito Especial. ${ }^{8}$

A finales de los años 60 , con una urbanización desbordada y con un modelo de sustitución de exportaciones prácticamente agotado, apareció un plan decidido a convertir a la vivienda en el nuevo epicentro del desarrollo nacional: el Plan de las Cuatro Estrategias. Este pretendió captar la creciente mano de obra rural que migraba a la ciudad vinculándola con el sector de la construcción de vivienda. Por otra parte, para su financiación se creó el sistema UPAC (Unidad de Poder Adquisitivo Constante). En este mismo contexto, los gobiernos nacionales con el apoyo del Banco Internacional de Reconstrucción y Fomento (BIRF) y el Programa de las Naciones Unidas para el Desarrollo (PNUD) concibieron los pilares de las políticas de urbanización en clave de desarrollo: nuevos polos de desarrollo urbano, masificación de vivienda y cualificación del transporte. En este marco se concibió el Plan de Estructura para Bogotá, que trazó los lineamientos para la planificación del desarrollo urbano hasta 1990.
5. Registro Municipal. Año LIII, No. 16, 31 de agosto de 1933, pp. 483-484; No. 23, 15 de diciembre de 1933, pp. 738-739; Año LIV, No. 37, 15 de julio de 1934, p. 23. Valga señalar que la creación del Departamento de Urbanismo fue reiterada en el inciso $n$ del artículo $1 .^{\circ}$ del acuerdo 34 del 9 de octubre de 1933, mediante el cual se definieron las obras para la celebración del IV centenario de fundación de la ciudad. CB. Registro Municipal. Año LIII, No. 20, 31 de octubre de 1933, pp. 639-642.

6. El trabajo de BRUNNER en Bogotá está condensado en una serie de artículos, pero particularmente en su Manual de Urbanismo. En uno de sus tomos BRUNNER se involucra con los problemas de la vivienda y el saneamiento de las viviendas para obreros y reseña su participación en el reasentamiento de los obreros desalojados del Paseo Bolivar en el barrio moderno de El Centenario (BRUNER, 1939, 1939-1940).

7. El 9 de abril de 1948 fue asesinado en pleno centro de la ciudad el popular líder liberal Jorge Eliécer 
Gaitán, suceso reseñado en la historia como "el Bogotazo" por las protestas con las que reaccionaron los habitantes la ciudad y seguidores del lider y la represión violenta por parte de la institucionalidad, todo lo cual dejó como saldo la destrucción del centro histórico de Bogotá.

8. Por medio del Decreto Legislativo 3640 desde 1954 se anexaron al perímetro urbano de la ciudad los municipios de Engativá, Fontibón, Suba, Usme, Usaquén y Bosa.
El plan de estructura estableció varias estrategias que deberían encaminar los procesos de planificación de la ciudad. Particularmente en materia de construcción de soluciones de vivienda para sectores de escasos recursos, contemplaba la expansión de la ciudad hacia el occidente, especialmente en las áreas de Fontibón, Suba, Engativá y Soacha; la construcción de viviendas de alta densidad cercanas a los nuevos centros de trabajo y la puesta en marcha de programas de vivienda tipo "terreno y servicios", el mejoramiento del sistema de transporte y tránsito y la asignación de mayores recursos a programas de dotación de equipamientos sociales y comunales. Con base en el Acuerdo 18 de 1972, que instaba a la Administración Distrital, en cabeza de la Junta de Planificación y del Departamento Administrativo de Planeación Distrital, a formular su política a través de Planes Generales de Desarrollo del Distrito, el plan de estructura recomendó enfáticamente la formulación de un Plan General que se constituyera en el principal instrumento de control del desarrollo urbano de la ciudad (DAPD, 1972).

En este contexto aparece uno de los proyectos más representativos de la época, el Plan Integrado de Desarrollo Urbano de la Zona Oriental de Bogotá (PIDUZOB). Una de sus principales obras, la construcción de la avenida de Los Cerros, puso en confrontación a diferentes actores sociales: unos decididos a rentabilizar la obra en su beneficio particular; otros, más de 1100 familias, decididos a confrontar una iniciativa que los expropiaría de sus viviendas. El intenso debate y las álgidas movilizaciones que suscitó llevaron a que la principal entidad financiadora, el Banco Interamericano de Desarrollo (BID) condicionara el préstamo de los recursos a la construcción de un plan de desarrollo urbano con un carácter más integral (GómEZ y SERNA, 2012). Así, el PIDUZOB se constituyó en el primer plan de desarrollo urbano que contempló el mejoramiento de barrios, particularmente de aquellos ubicados sobre los cerros orientales de la ciudad. Se dio prioridad a procesos de acceso a servicios públicos básicos, equipamientos para educación y salud, la pavimentación de vías y el acceso a tierras para la construcción de vivienda libre de riesgos (DAPD, 1972).

Este marco de acción permitió que surgiera una de las primeras disposiciones dirigidas al mejoramiento de barrios, el Acuerdo 21 de 1972, que adoptó el plan de mejoramiento de áreas de desarrollo incompleto en la ciudad y creó la Comisión de Mejoramiento Urbano. El propósito del plan se orientó a regularizar aquellos asentamientos que demandaban mejoramiento, habilitación de servicios públicos o legalización de títulos de propiedad. Parte de este proceso demandó del Departamento Administrativo de Planeación Distrital la elaboración de planos de loteo de los diferentes barrios, así como la incorporación de 
Procesos de construcción de ciudad y vivienda informal. El caso de las barriadas informales de los cerros orientales de Bogotá, Colombia

estos en el plano general de la ciudad. Más adelante, a través del Acuerdo 25 de 1975, se reconocieron aquellos asentamientos que se encontraban por fuera del perímetro urbano y sanitario de la ciudad y se señaló la necesidad de ser incorporados al programa de mejoramiento de barrios. De esta manera, aparecieron los primeros grandes proyectos de mejoramiento, rehabilitación y legalización de asentamientos informales, particularmente de aquellos que se habían desarrollado en la periferia de la ciudad y que ni siquiera habían sido contemplados como parte de ella.

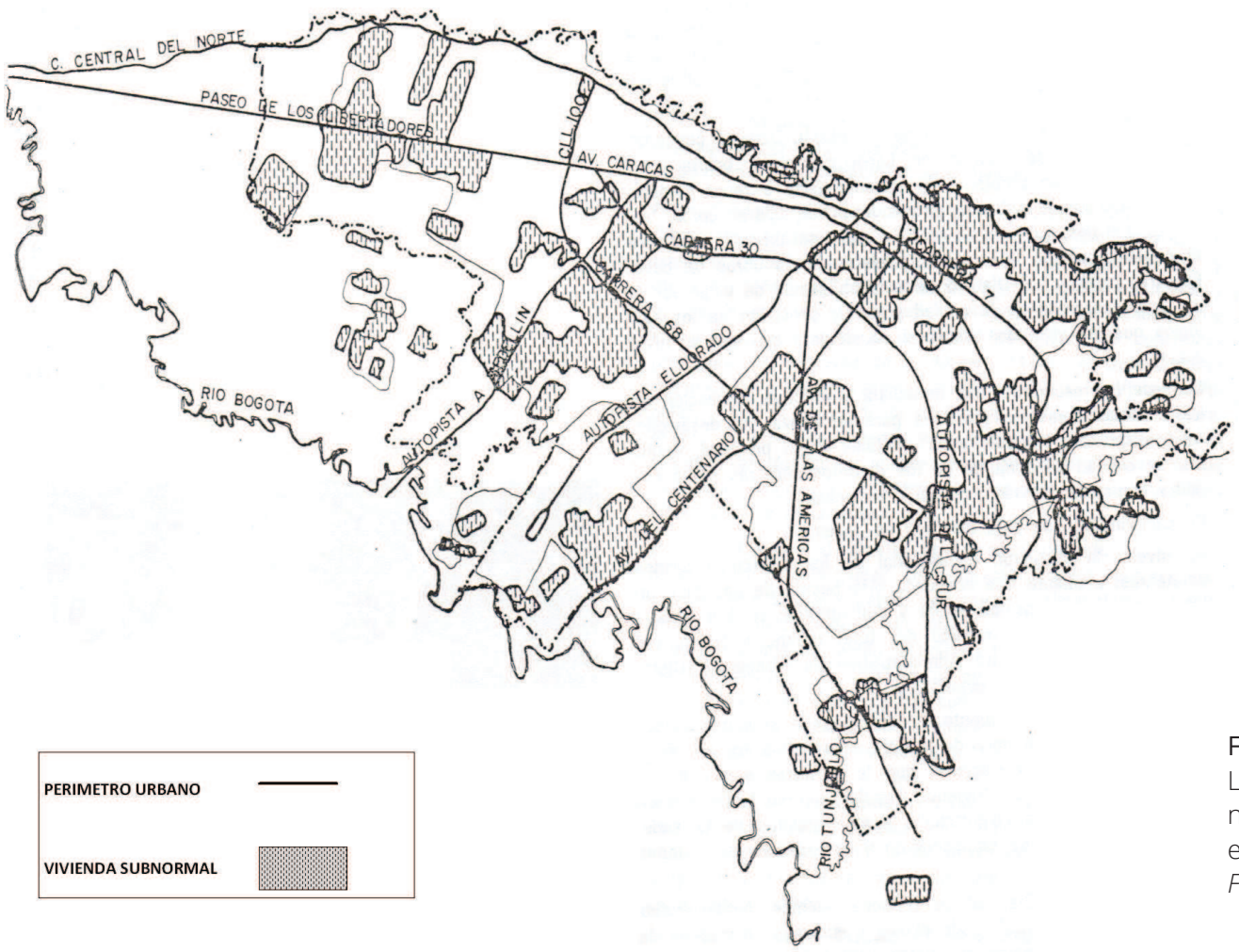

Figura 3

Localización de áreas subnormales en Bogotá para el año 1972

Fuente: DAPD, 1972. 


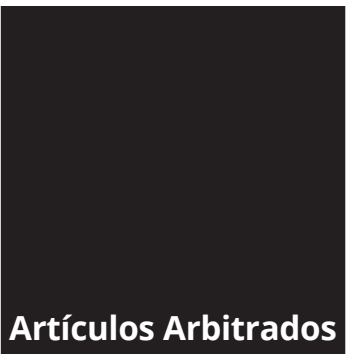

Diana Gómez Navas y Adrián Serna Dimas

9. TORRES (2012) presenta un interesante balance crítico sobre las estrategias de legalización de barrios implementadas en la ciudad de Bogotá, particularmente en el período de 1990 a 2012, cuando se incrementa de manera vertiginosa la construcción de vivienda y barrios informales, muchos de ellos impulsados por urbanizadores "piratas" que aprovecharon la limitada politica de acceso al suelo y a la vivienda urbana, así como la política de formalización de barrios, que en muchos casos terminaba siendo una decisión en la que se mezclaban intereses políticos y económicos de todo tipo.

10. En ese contexto se expidieron varios decretos que ordenaron legalizaciones masivas de asentamientos de origen informal: Decretos 689 de 1996 para diferentes localidades de la ciudad; 1028 de 1997 para la localidad de Bosa; 679 de 1998 para la localidad de Engativá; 683 de 1998 para la localidad de Kennedy, 684 de 1998 para la localidad de Suba; 831 de 1998 para las localidades de Usme, Kennedy y Fontibón; 1063 para
Durante los años 80 la idea de la construcción de espacios urbanos autosuficientes fue relegada por un criterio más atento a la relación costo-beneficio. De esta manera, las zonas de la ciudad más desarrolladas se convirtieron en el foco de atención para la construcción de vivienda de alto costo o para la adecuación de proyectos industriales o de servicios. El desarrollo urbano privilegiaba así los intereses del capital privado y desplazaba la planificación desde lo público. Precisamente, el Plan General de Desarrollo de la Ciudad (Acuerdo 7 de 1979) dispuso una regulación del uso del suelo con un espíritu economicista que ponía los intereses del mercado inmobiliario sobre las necesidades de desarrollo urbano que la ciudad requería. Finalmente, la formalización y la legalización fueron desmanteladas de las exigencias de la planificación, de las dotaciones fundamentales, de la inserción de servicios públicos y de la construcción de vías. De esta forma se expidió el Acuerdo 1 de 1986, que dispuso la legalización de más de trescientos asentamientos ubicados en diferentes localidades de la ciudad y su incorporación en el registro catastral de esta. La disposición pretendió facilitar el proceso de formalización e invocó a las diferentes entidades distritales para que incluyeran en sus presupuestos programas enmarcados en el plan de mejoramiento de desarrollos incompletos de la Administración Distrital, de conformidad con los usos del suelo y la zonificación que establecía el Acuerdo 7 de 1979.

En la década de los 90 la ciudad adoptó un nuevo modelo de desarrollo urbano por medio del Estatuto de Ordenamiento Físico (Acuerdo 6 de 1990) ${ }^{9}$, que contemplaba la conservación y rehabilitación de los recursos ecológicos y ambientales, la gestión y aprovechamiento del espacio público, la conservación y restauración de inmuebles o áreas consideradas de valor arquitectónico, urbanístico, histórico o cultural, la reutilización de sectores con deficiencias estructurales y la promoción del potencial industrial y comercial de las áreas consolidadas. El nuevo ordenamiento físico de la ciudad tuvo un enfoque netamente jurídico, más orientado al establecimiento de normas y procedimientos. Con ello, el tema de la ocupación informal del suelo se asumió desde la formulación de procedimientos más expeditos, para lo cual dichos barrios fueron incorporados en un régimen de usos y normas urbanísticas diseñadas para lograr su armonización con el Plan de Ordenamiento Físico de la ciudad (Decreto 688 de 1996). ${ }^{10}$

Para comienzos de siglo la ciudad expidió un nuevo Plan de Ordenamiento Territorial (Decreto 619 de 2000), con el cual se potenció el modelo de desarrollo urbano basado en la normativa urbanística que privilegiaba la acción del capital privado en relación con la explotación del suelo urbano, su reordenamiento, redensificación o revitalización. En este marco se realizaron otros procesos de legalización masiva de asentamientos 
Procesos de construcción de ciudad y vivienda informal. El caso de las barriadas informales de los cerros orientales de Bogotá, Colombia

informales ${ }^{11}$ y se creó el Comité Técnico de Legalización, instancia en la que concurren no solo las dependencias relacionadas con la materia, sino las empresas de servicios públicos domiciliarios, $\mathrm{y}$, con ello, la legalización se constituyó principalmente en un mecanismo para reconocer a un asentamiento informal como parte de la estructura urbana de la ciudad. ${ }^{12}$

A la fecha se ha avanzado notablemente en los procesos de reconocimiento formal de barrios; sin embargo, los procesos de invasión no se han detenido y la ciudad continúa con una presencia importante de barrios informales que, sumados a los barrios legalizados, constituyen una parte significativa de asentamientos con problemas de habitabilidad. Desde los años 80 el tema de los asentamientos informales se redujo a una cuestión normativa tanto en el ámbito de la propiedad del suelo como de su armonización urbanística, lo que llevó a que los asentamientos informales se incorporaran a procesos jurídicos y técnicos de formalización, que resultaron sumamente largos y engorrosos y postergaron aún más sus posibilidades de estar integrados a la ciudad y a la vida urbana. Precisamente esto se refleja en el caso de las barriadas informales de los cerros orientales, unas de las más antiguas de la ciudad.

\section{LAS LUCHAS POR LA VIVIENDA EN UNA BARRIADA INFORMAL. LOS CASOS DE LOS BARRIOS DE LOS CERROS ORIENTALES DE BOGOTÁ}

Desde finales del siglo XIX, las familias con propiedades en los cerros orientales favorecieron el asentamiento de mano de obra en sus predios para la explotación de los chircales, las canteras, las minas y los bosques. La relación entre los propietarios y los trabajadores fue en esencia de contrato verbal; los propietarios de los predios permitieron el asentamiento de familias enteras asumiendo como contraprestación arriendos, trabajo parcial o inclusive pagos en especie con los productos explotados. De esta manera, un núcleo de barriadas obreras informales se extendió por la cuenca alta del río Arzobispo.

Para comienzos de los años 50, las políticas de recuperación y protección de los cerros orientales trajeron el cierre de las explotaciones. Los propietarios de los predios, obligados a acatar la medida y con ánimos de beneficiar sus terrenos con obras públicas como la del Parque Nacional, optaron por disponer parte de sus predios para proyectos urbanizadores, y otros más, particularmente aquellos enclavados en lo más alto, para preservarlos como formas de pago de deudas laborales que poseían con sus antiguos trabajadores. las localidades de Usaquén, Usme, Bosa, Suba y Ciudad Bolívar.

11. El Decreto 970 de 2000 dispuso la legalización de cerca de sesenta barrios ubicados en las localidades de Usaquén, San Cristóbal, Usme, Bosa, Kennedy, Fontibón, Engativá, Suba, Rafael Uribe y Ciudad Bolivar.

12. Ver Resoluciones 78 y 97 de 2003 del Alcalde Mayor y el Decreto 367 de 2005. 


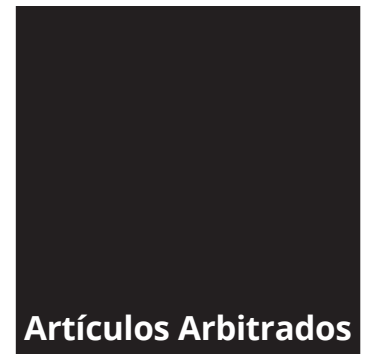

Diana Gómez Navas y Adrián Serna Dimas

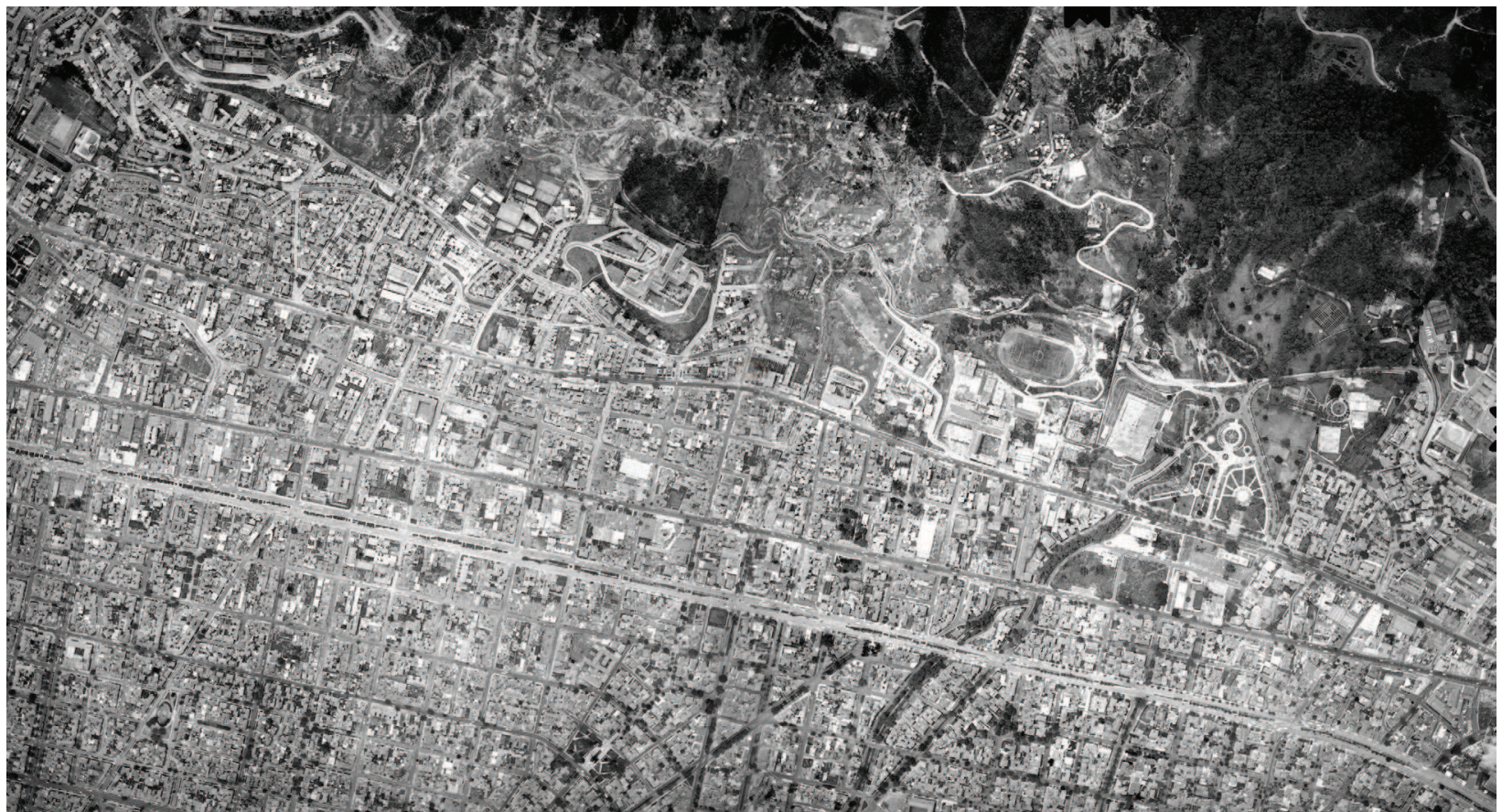

Figura 4

Aerofotografía de la zona de los cerros orientales donde se ubicaron las antiguas barriadas informales Fuente: IGAC, Vuelo C-1202, 1967.
Este es el caso de los barrios El Paraíso, San Martín de Porres, Pardo Rubio Nororiental y Barrocolorado, este último también conocido como Mariscal Sucre, asentamientos construidos de manera informal por familias trabajadoras de las industrias extractivas de los cerros orientales del norte de la ciudad, quienes vivieron durante varias décadas al margen del desarrollo urbano, pero que por iniciativa propia - aunque con incidencia de agencias como partidos políticos, movimientos de izquierda, organizaciones no gubernamentales y organizaciones sociales - se constituyeron en barrios con una organización consistente. Su ubicación en los cerros orientales los convirtió en el blanco de todo tipo de disputas, desde aquellas que veían dichos terrenos para la urbanización de vivienda de alto costo, hasta las que propusieron proyectos urbanísticos tan importantes como la construcción de 
Procesos de construcción de ciudad y vivienda informal. El caso de las barriadas informales de los cerros orientales de Bogotá, Colombia

la avenida de Los Cerros, lo cual puso en riesgo su condición de poseedores, sus posibilidades de ser reconocidos como legítimos propietarios, impidió su desarrollo urbano y les generó problemas de orden jurídico sobre la disposición del suelo.

Uno de los primeros barrios obreros de la cuenca alta del río Arzobispo fue El Paraíso. Sus orígenes se remontan a finales del siglo XIX sobre los terrenos de la entonces hacienda El Paraíso, propiedad de la familia Murillo. Sus terrenos, ubicados en una próspera zona extractiva que se tendía entre los cerros orientales y la hacienda La Merced y entre el río Arzobispo y la quebrada de Barrocolorado, permitieron la explotación de arena y carbón, con lo cual sus propietarios consintieron el asentamiento de familias como mano de obra necesaria. Con el paso de los años, cuando se dieron por terminadas las industrias extractivas de los cerros orientales, parte de la hacienda fue vendida a otras familias, pero los ocupantes preservaron sus viviendas en la parte alta del cerro.

Figura 5

Barrio El Paraíso

Fuente: IGAC, Vuelo 1131, 1990.

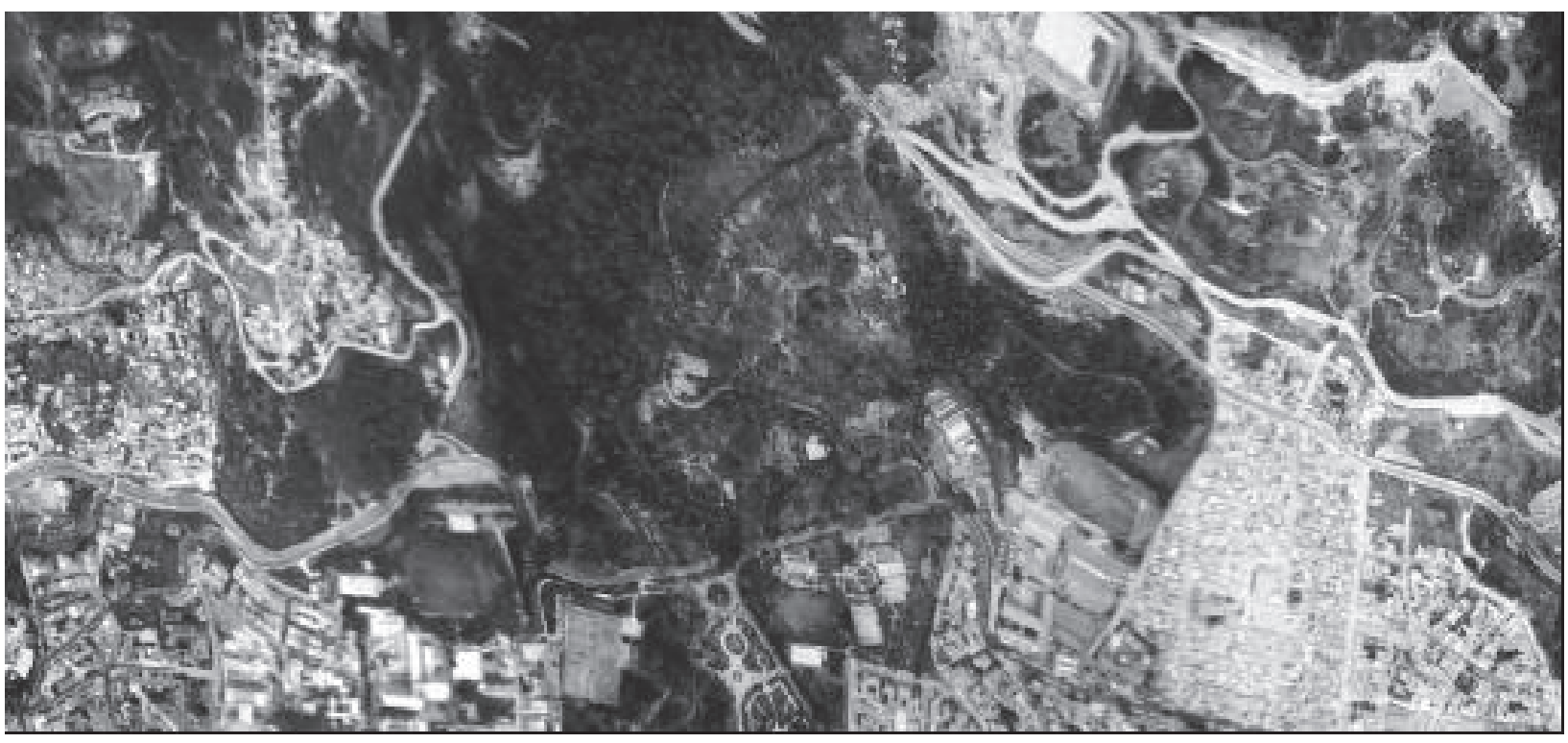


El Paraíso emprendió procesos de organización relativamente tempranos, a fin de velar por la formalización de sus viviendas. De hecho, para comienzos de los años 60, el Concejo Municipal, por medio del Acuerdo 68 del 14 de noviembre de 1961, lo reconoció y lo incluyó en el circuito H de sectorización urbana (Acuerdo 1 de 1961). No obstante, el barrio adolecía de vías de acceso, de servicios públicos fundamentales y de equipamientos urbanos, los cuales fueron negados por el Distrito toda vez que este se encontraba por encima de la cota de urbanización de la ciudad. Esto supuso nuevas movilizaciones de sus habitantes.

El líder más reconocido en la zona fue don Absalón Acero Chiquillo, quien falleció en el decenio de 1980. Miembro de la USO (Unión Sindical Obrera) durante su juventud y presidente del sindicato de Bavaria, cuando llegó al barrio El Paraíso en 1952, su mayor preocupación era conseguir el acceso a los servicios públicos. La lucha por el agua fue inicialmente su gran objetivo. En 1966, siendo alcalde Virgilio Barco y cansado por la falta de una respuesta efectiva por parte del Estado, Absalón Acero convocó a las comunidades de los barrios El Paraíso y San Martín a represar las aguas del río Arzobispo. Tal llamado concitó la participación masiva de las comunidades, especialmente de El Paraíso, que condujo ese proceso. Logró el aporte de la Embajada de Estados Unidos, en el marco de la Alianza para el Progreso, para realizar los estudios de factibilidad y el suministro de la tubería necesaria, además de la colaboración por parte del gobierno distrital, que hasta ese momento no había suministrado el acueducto a los barrios, so pretexto de estar ubicados por encima de la cota señalada por Planeación Distrital para la dotación de servicios (Molano, 1997: 175).

La organización del barrio recibió un especial estímulo con la Resolución 4743 de 1968 , mediante la cual el Ministerio de Justicia reconoció la personería jurídica de su junta de acción comunal. La junta mantuvo su dinamismo en la preservación del estatuto del barrio, en la consecución de obras públicas en materia de servicios públicos y frente a los requerimientos jurídicos sobre la ocupación de estos predios. Gracias a esto el barrio contó con acceso a servicios públicos fundamentales, como agua y electricidad, mucho antes de su formalización; su adecuación contó con el trabajo de toda la comunidad, la cual además aunó esfuerzos para construir centros educativos en sus diferentes grados; asimismo, se congregó en torno de la construcción de los lavaderos comunitarios, que desde la década de los 60 le quitaron distancia al recorrido que las mujeres hacían hasta el río Arzobispo o el Seminario Calasanz (DuQue, s. f.). 
Procesos de construcción de ciudad y vivienda informal. El caso de las barriadas informales de los cerros orientales de Bogotá, Colombia

En el marco del Acuerdo 6 de 1990 y con el ánimo de dar cuenta del objetivo de conservación y rehabilitación de recursos ambientales, pero al mismo tiempo de continuar con el trámite de numerosas legalizaciones emprendidas desde tiempo atrás, el Distrito contrató un estudio con la Universidad de Los Andes para adoptar un Plan de Ordenamiento Físico del Borde Oriental de la ciudad y otras áreas de interés medioambiental, el cual sería acogido a través del Decreto 320 de 1992, que entre otras disposiciones estableció como zona N..$^{\circ} 4$ los terrenos comprendidos entre el río Arzobispo y la quebrada La Vieja, a fin de promover en ella un programa de habilitación que no solo incluyera el tema de la recuperación del sistema orográfico, sino también el mejoramiento de la calidad de vida de los asentamientos allí establecidos: "[...] Comprendido entre el sector San Martín y el río 'Arzobispo'. Tiene una cabida aproximada de 14 hectáreas, de las cuales el $63 \%$ están representadas por el Barrio El Paraíso. El restante $36 \%$ está constituido por terrenos sin desarrollar, al norte, occidente y sur [...] Los localizados al occidente y sur se caracterizan por sus deficiencias morfológicas y por la arborización que presentan. El barrio El Paraíso es el más desarrollado de todos los presentes en la Zona del estudio aunque, e igualmente, presenta deficiencias que ameritan su habilitación. Este sector alberga cerca de 3000 habitantes" (SMOB, 1993).

Cerca del barrio El Paraíso apareció a comienzos del siglo XX el barrio San Martín de Porres, también fruto de la vinculación de obreros para la exploración de las canteras por parte de Enrique Pardo Roche, propietario de terrenos en esta zona. Luego, con el cierre de estas, a comienzos de los años 50, sus herederos decidieron cancelar las acreencias en materia laboral con los trabajadores entregando lotes en la parte alta de sus propiedades.

“Como ellos [los Pardo Rubio] vendieron, como acabaron de vender la calle 47 y 46. Eso lotearon, entonces ya ese terreno, lo que quedó, porque lo vendieron, esa faja de tierra que es de allá de doña Leonor Moreno para acá, ellos la destinaron (...) Prácticamente ese terreno que yo tengo lo tengo por código laboral, lo tengo por prestaciones sociales. // Ellos [los Pardo Rubio] ya habian asignado este terreno acá para que la gente que vivíamos abajo nos trasladáramos p'arriba. Yo no quería venirme, yo no quería subirme ni por nada de la vida (...) Casi me quedo sin lote, porque como yo fui el último que me vine de abajo ya no quedaba sino este lote, que es este acá donde estamos. // Ellos [los Pardo Rubio] posesionaron a la gente, porque aquí somos 49 propietarios que ellos posesionaron, directamente posesionados por ellos. (...) Ellos tuvieron mucha voluntad (...) Inclusive ellos nombraron un abogado, un tal Doctor Perea, que era abogado de por 
aquí de Teusaquillo. Lo nombraron para que el abogado nos hiciera las escrituras a los 49 propietarios. Pero yo le digo, como el gobierno no quiere que este sector sea para la clase popular, no pudo el Doctor ese hacer las escrituras. Devolvieron la plata, porque eso nos pidieron en ese tiempo como de a mil pesos por persona” (Molano, 1997: 148-149).

San Martín de Porres no fue fruto de invasiones; sus habitantes tomaron posesión de los terrenos como forma de pago por su trabajo, pero por mucho tiempo no tuvieron las escrituras que los acreditaran como propietarios, y aunque el problema de la posesión estaba absuelto, no así otras materias fundamentales, como los servicios públicos y los accesos viales, que se convirtieron en un aspecto complejo, tanto más con las definiciones de las áreas urbanizables establecidas por el Distrito desde mediados de los años 50. Para responder a esto, los vecinos del barrio se dispusieron a conformar una junta de acción comunal, que finalmente fue reconocida por medio de la resolución 4730 de 1964 del Ministerio de Justicia (ADP, Carpeta San Martín de Porres).

Durante los años 70, los vecinos del barrio, junto con los del barrio El Paraíso, emprendieron diferentes movilizaciones sociales para conseguir servicios públicos fundamentales como el agua; también jugaron un papel protagónico en las protestas suscitadas por la construcción de la avenida de Los Cerros. Al igual que El Paraíso, el problema del agua se solucionó inicialmente con la construcción de albercas comunales, y frente a la electricidad los habitantes ingeniaron formas extractivas de alumbrados de barrios relativamente cercanos. Con el paso del tiempo, el barrio fue creciendo hasta el punto que las familias empezaron a vivir en hacinamiento, lo que hacía más difícil la presencia de servicios y equipamientos y llevó a que buscaran soluciones frente a la necesidad de vivienda de las nuevas generaciones. Así, a mediados de los años 80, las familias se organizaron para emprender un proceso de invasión de terrenos aledaños. Con ello se vislumbraron nuevos liderazgos que organizaron de manera coordinada la posesión y la distribución de los lotes a las familias más necesitadas.

“[...] Algunos pagábamos arriendo o vivíamos en un hacinamiento terrible, y cuando vimos que esos terrenos cerca a la Circunvalar, eran unos potreros que en últimas estaban desocupados, a la deriva y durante años habian sido nuestros sitios de juego y diversión, pues conversamos y decidimos entrar a tomar derecho de posesión sobre estas tierras, a finales del año 85. [...] Todos los lotes fueron iguales para todo el mundo y eran de $6 x 12$ metros. Luego, hicimos grupos de a tres personas para vigilar, cada dos horas, que no llegara la policía, o alguno de los abogados de los que ya se habían 
Procesos de construcción de ciudad y vivienda informal. El caso de las barriadas informales de los cerros orientales de Bogotá, Colombia

comenzado a presentar como supuestos dueños y nos fueran a sacar. Más tarde empezamos a cercar y poner en las esquinas del terreno unas primeras casitas" (CHAPARRO, Mendoza y Pulido, 1999).

Es así como al lado de San Martín de Porres se levantó un segundo sector, y años más tarde un tercero y un cuarto, que conformaron nuevas barriadas de extensión pequeña. La consecución de servicios públicos básicos como agua y luz fue parte de las luchas que los habitantes del barrio emprendieron de manera mancomunada con los vecinos de El Paraíso, Pardo Rubio Nororiental y Mariscal Sucre, que compartían su misma condición.

Junto al barrio San Martín de Porres se configuró el barrio Pardo Rubio Nororiental. Como en el caso del primero, el Pardo Rubio Nororiental tuvo su origen en la decisión de los hermanos Alejandro y Eduardo Pardo Rubio de atender las deudas que tenían por materias laborales con los trabajadores de las antiguas explotaciones de su sector. A mediados de los años 50, los Pardo Rubio desenglobaron los predios de su propiedad y entregaron en cesión los terrenos ubicados en la parte baja del cerro. Con relación a los barrios anteriores, este tuvo algunas ventajas, entre ellas la proximidad de vías, de infraestructura y de algunos equipamientos urbanos, situación que no se presentaba en la parte más alta, donde estaban las prohibiciones para cualquier dotación urbana. No obstante, como en otros casos, el barrio enfrentó un problema sustancial: la inexistencia de un acto formal sobre la entrega de los predios, lo que impedía que el Distrito y cualquier privado reconociera a sus habitantes como propietarios y que lograran conseguir mejoras públicas. Para resolver estos problemas, los vecinos del barrio se organizaron como junta de acción comunal, la cual fue aprobada por Resolución del 5 de 1971 de la Alcaldía Mayor de Bogotá (ADP. Carpeta Barrio Pardo Rubio).

Inicialmente las familias poseedoras estaban asentadas en los predios de la parte baja de los cerros; esa ubicación privilegiada en una zona con expectativas de urbanización de alto costo llevó a que se presentaran discrepancias en cuanto a la propiedad de los terrenos con la familia Pardo. Frente a ello, sus habitantes empezaron procesos organizativos a fin de dar trámite a los problemas de propiedad de sus lotes. De esta manera, en el año 1967 la comunidad llegó a un acuerdo con la familia Pardo para trasladarse a lotes ubicados en la parte alta del cerro, sobre el compromiso de entregar los terrenos que habitaban en ese momento en la parte baja (ADP. Carpeta Barrio Pardo Rubio). Para finales de la década de los 80, el barrio se consolidó en la parte alta y la junta empezó el proceso de búsqueda 
de legalización y mejoras, para lo cual debieron pactar el procedimiento de desenglobe de los terrenos y la posterior emisión de escrituras públicas. Con ese objetivo, la junta se reunió nuevamente con los hermanos Pardo para convenir "1. El desenglobe por parte de la oficina de Catastro distrital, individualizando los predios de propiedad del barrio Pardo Rubio y los predios de propiedad de los señores Andrés Pardo Montoya y Helena Pardo Montoya. Una vez cancelado el impuesto predial y demás, la familia Pardo en colaboración con los miembros de la Junta de Acción Comunal se compromete a dar la escritura pública del terreno asignado al barrio Pardo Rubio que poseen los mismos desde hace más de 20 años en calidad de propietarios por acuerdo entre el señor Eduardo Pardo y posteriormente con sus herederos, [...] 4. Asi mismo se recalca que los predios que están fuera del perímetro del barrio Pardo Rubio por la zona oriental, zona occidental y por la zona norte son de propiedad y posesión de los mismos; en algunos sitios de estos predios se encuentran ubicadas algunas familias. / En acuerdo con estas familias para poder obtener los servicios públicos es que se deben trasladar a los predios del barrio Pardo Rubio y así dejarle libre estos terrenos a la familia Pardo Montoya. Si estas personas por alguna razón no se trasladan a los lotes que les corresponde a ellos dentro del barrio serán devueltos a la familia Pardo Montoya por convenio hecho con la junta directiva que estaba en ese momento como también con dichas familias que se encuentran ubicadas en estos sitios" (ADP. Carpeta Barrio Pardo Rubio).

Después de clarificar el tema de la posesión de los terrenos, el barrio concentró todos sus esfuerzos en el proceso de formalización. Con ello pretendía, sobre todo, conseguir la mejoría en materia de acceso a servicios públicos. Dicho proceso se desarrolló de la mano de varias protestas y marchas hacia las entidades distritales y empresas de servicios públicos, pero eso tardó varias décadas en ser resuelto.

Por su parte, el barrio Barrocolorado tiene su origen en la ocupación que hicieron familias de obreros de los terrenos que quedaban al margen norte de la quebrada de Barrocolorado. A diferencia de las otras barriadas informales, los ocupantes de esta tuvieron serios problemas en relación con la posesión de los lotes, pues las primeras familias nunca estuvieron vinculadas laboralmente con sus propietarios y nunca contaron con ningún tipo de cesión. Desde los años 20 los terrenos fueron continuas veces sucedidos y vendidos en cantidades cada vez más amplias de propietarios (DE OBREGón, 1990), y en el año de 1962 el predio contó con el reconocimiento de derechos proindivisos, cuando los propietarios se conformaron como comuneros e interpusieron ante un juzgado de Bogotá una solicitud de división del inmueble, que fue reconocida pero que nunca se efectuó por la congelación 
Procesos de construcción de ciudad y vivienda informal. El caso de las barriadas informales de los cerros orientales de Bogotá, Colombia

que los terrenos tenían por el proyecto de construcción de la avenida de Los Cerros. A ello se sumó que en este lapso los distintos propietarios fueron continuamente arrendando su parte a familias que se asentaron y construyeron sobre ellos.

Al tiempo que los comuneros propietarios hacían todo tipo de esfuerzos para que el distrito autorizara la urbanización de alto costo en Barrocolorado, los residentes en el terreno, conformados tanto por familias emplazadas desde décadas atrás como por los nuevos ocupantes que llegaron desde comienzos de los años 60 en condición de arrendatarios, emprendieron el proceso para legalizar su posesión y constituirse como barrio. En un comienzo, los residentes apelaron a reconocerse como vecinos del barrio Barrocolorado, pero la respuesta de las autoridades distritales fue que tal barrio no existía; entonces los residentes se reconocieron como vecinos del barrio Mariscal Sucre. Precisamente, con este nombre se conformó la junta de acción comunal, la cual fue finalmente reconocida con personería jurídica el 16 de febrero de 1989 (ADP. Carpeta Barrio Mariscal Sucre).

De esta forma se inició una disputa por la propiedad entre los comuneros propietarios que aspiraban a urbanizar los terrenos y los poseedores, quienes habían solicitado en el año 1977 un proceso de formalización de su barrio. Dicha disputa se prolongó en el tiempo, lo que supuso que la intervención del Distrito empezara aclarando si el barrio era fruto de una ocupación que les otorgaba derechos de posesión a sus habitantes o si, por el contrario, eran los comuneros quienes realmente tenían los derechos de propiedad sobre los predios. En efecto, el Departamento Administrativo de Planeación Distrital emprendió el proceso a fin de aclarar la situación del asentamiento Mariscal Sucre. Para responder a ello, la comunidad contó en sus inicios con el apoyo jurídico y político de varias instancias ${ }^{13}$, con lo cual el proceso organizativo se hizo más fuerte, aunque se extendió desde finales de los años 70 hasta mediados de los años 90 .

Pero los barrios El Paraíso, San Martín de Porres, Pardo Rubio Nororiental y Mariscal Sucre no solo tienen cercanías geográficas, orígenes similares e incluso procesos organizativos y de lucha comunes, sino también han sido testigos y son hoy el reflejo de las contradicciones de las políticas de formalización de barrios que ha puesto en marcha la administración distrital. Unas políticas que entienden la formalización en términos netamente jurídicos, que ponen en manos de los habitantes parte de la carga del mejoramiento urbano y que, por lo tanto, hacen del proceso algo excesivamente engorroso y largo, así como difícilmente representativo de una auténtica mejoría de las condiciones de vida de estas poblaciones o de su real integración a la ciudad y a la vida urbana (EL EsPECTADOR,
13. Del Centro de Investigación $y$ Educación Popular (CINEP), del Centro Jurídico Comunitario y de partidos politicos de izquierda como la Unión Patriótica. 
14. El Paraíso y Mariscal Sucre fueron legalizados a través de la Resolución 1126 de 1996; por su parte, San Martín de Porres $y$ Pardo Rubio Nororiental lo obtuvieron por medio de la resolución 0451 de 1999.
2008; 2011). Tanto es así que solo hasta la década de los 90 el Distrito efectúa el mandato de formalización de estas barriadas y, más aún, en la actualidad estas siguen contando con problemas de servicios básicos, y algunas de ellas aún no cuentan con títulos de propiedad. ${ }^{14}$

En otras palabras, a través de los casos de estas antiguas barriadas informales de la ciudad se puede vislumbrar el carácter de unas políticas de mejoramiento y formalización de barrios que no han representado verdaderos esfuerzos por garantizar que estos asentamientos tengan parte en el desarrollo urbano de la ciudad; simplemente se han constituido como un reconocimiento jurídico que los incluye en el perímetro urbano, que abre un largo camino hacia la obtención de títulos de propiedad y que mantiene a las comunidades en procesos de autogestión que, paradójicamente, fueron y son los que han hecho de este tipo de asentamientos barrios construidos por la gente.

\section{A MODO DE CONCLUSIÓN}

Los estudios de los procesos de formalización, legalización y mejoramiento de barrios han permitido vislumbrar las distintas estrategias emprendidas por el Estado para lograr la incorporación de las poblaciones que se hicieron al margen de la ciudad. Para la ciudad de Bogotá, los primeros procesos de expansión urbana estuvieron marcados más por la implementación de apuestas sectorizadas y enclasantes que por la definición por parte del Estado de un modelo de desarrollo urbano integral. Esto condujo a un desarrollo urbano inequitativo, segmentado y segregador, en el cual unos pocos tuvieron todos los beneficios y las mayorías, inmensas desventajas. Pese a que desde los años 30 el Estado decidió asumir un papel mucho más protagónico en la definición de un modelo urbano emprendiendo programas de obras públicas de gran envergadura, configurando una institucionalidad pública propia, apelando a la formulación de planes urbanísticos y construyendo política urbana con criterios mucho más técnicos, los procesos de construcción de ciudad no lograron romper el patrón de inequidad, segmentación y segregación.

Precisamente, los procesos de construcción de ciudad que se dieron en la cuenca del río del Arzobispo revelan los conflictos que se tejen entre la ciudad formal y la ciudad informal: esta parte de la ciudad ha sido una de las que históricamente encuentra las mayores inversiones de recursos públicos y privados; sin embargo, muchas de ellas corrieron de manera paralela al desalojo sistemático de las clases obreras. Para finales 
Procesos de construcción de ciudad y vivienda informal. El caso de las barriadas informales de los cerros orientales de Bogotá, Colombia

de los años 20 las clases obreras estaban emplazadas al oriente sobre el Paseo Bolívar, al norte sobre el barrio Sucre, al occidente sobre el tendido del Ferrocarril del Norte y al sur en San Diego. Desde los años 30, con la construcción del Parque Nacional, con la urbanización de La Cascajera, con la construcción de la avenida Caracas y con el redesarrollo de San Diego, las clases obreras fueron desalojadas de esta parte céntrica de la ciudad. Estos procesos desconocieron derechos de posesión, emprendieron procesos de saneamiento e incrementaron los valores del suelo y del uso del suelo para las nacientes burguesías. Generaron que las barriadas obreras que persistieron en virtud de sus derechos de posesión solo fueran posibles enclavándose en los cerros, una zona, en su momento, desposeída de cualquier posibilidad de urbanización y con ello sometida al olvido y el abandono estatal.

Ahora, si este modelo fue de por sí contraproducente en una ciudad pequeña y con una población relativamente baja, no queda menos que decir que resultó catastrófico cuando se reprodujo en una ciudad inaudita que triplicó su población en menos de dos décadas. La ciudad de los años 50 y 60 vio cómo el patrón de aprovechamiento minoritario de las centralidades urbanas y de exclusión mayoritaria hacia las márgenes (espaciales, sociales y económicas) condujo a una ciudad desgarrada en sus posibilidades como proyecto común. Ahí la relevancia de las luchas de los actores barriales, de las comunidades de base de la ciudad, que con sus luchas por el suelo y la vivienda pudieron - como en el caso de los cerros orientales - resistir a un modelo de desarrollo urbano soportado en las prebendas del mercado y en el expolio estructural del patrimonio común que es la ciudad.

\section{BIBLIOGRAFÍA}

ARANGO, Carlos (1986) La lucha por la vivienda en Colombia. ECOE, Bogotá.

ARIAS, Fernando (2008) Le Corbusier en Bogotá: El proyecto del "grand immeuble", 1950 - 1951. Universidad Nacional de Colombia, Bogotá.

BRUNNER, Karl (1939) Manual de urbanismo. T. I. Síntesis vivienda saneamiento. Ediciones del Concejo de Bogotá, Bogotá.

BRUNNER, Karl (1940) Manual de urbanismo. T. II. Sintesis vivienda saneamiento. Ediciones del Concejo de Bogotá, Bogotá.

CASTILLO, Juan (2003) Bogotá. El tránsito a la ciudad moderna 1920 - 1950, Universidad Nacional de Colombia, Bogotá. 
CASTRO, Santiago (2009) Tejidos oníricos. Movilidad, capitalismo y biopolítica en Bogotá (1910-1930). Universidad Javeriana, Bogotá.

CAMARGO, Angélica y HURTADO, Adriana (2012). "Informalidad del siglo XXI. Características de la oferta informal de suelo y vivienda en Bogotá durante la primera década del siglo XXI". En: Territorios, (27), pp. 71-103.

CAMARGO, Angélica, HURTADO, Adriana (2013). "Urbanización informal en Bogotá: agentes y lógicas de producción del espacio urbano". En: Revista INVI, 28 (78), pp. 77-107. CHAPARRO, Jairo; MENDOZA, Diana; PULIDO, Belky (1999) Un siglo habitando los cerros: vidas y milagros de los vecinos en el cerro del Cable. Corporación Comunitaria Raíces, Bogotá.

CEBALLOS, Olga (2008) Vivienda social en Colombia. Una mirada desde su legislación 1918-2005. Pontificia Universidad Javeriana, Bogotá.

COLÓN, Luis Carlos (2005). "El saneamiento del Paseo Bolívar y la vivienda obrera en Bogotá". En: Urbanismos, (2), pp. 104-115.

DE OBREGóN, María Antonia (1990) Barro Colorado (Hoy barrio Mariscal Sucre de Bogotá). Para adicionar a la "Tenencia de la tierra en la Sabana de Bogotá de 1539 a 1939" de Juan Carrasquilla Botero. Centro de Investigación y Educación Popular (CINEP), Bogotá.

DEPARTAMENTO ADMINISTRATIVO DE PLANEACIÓN DISTRITAL (DAPD) (1972). "Programa Integrado de Desarrollo Urbano Zona Oriental de Bogotá PIDUZOB". DAPD, Bogotá.

DEPARTAMENTO ADMINISTRATIVO DE PLANEACIÓN DISTRITAL (DAPD) (1974). "Plan de Estructura. Informe técnico sobre el estudio de desarrollo urbano de Bogotá, Fase 2". DAPD, Bogotá.

DUQUE, María Claudia (s. f.) El Paraíso: Historias de trabajo comunitario. Bogotá, documento de Word, publicado en http://www.academia.edu/2028026/El_Paraiso._Historias de Trabajo Comunitario.

EL ESPECTTADOR (2008) Desalojados de El Paraíso.

EL ESPECTADOR (2011) El Paraíso, al borde del abismo.

GÓMEZ, Diana y SERNA, Adrián (2012). "Conflictos vecinales en los cerros orientales de Bogotá”. En Revista Ciudad y Territorio: Estudios Territoriales, Vol. XLIV, No. 174, pp. 727-742.

GUTIÉRREZ, María-Teresa (2010). "Proceso de institucionalización de la higiene: estado, salubridad e higienismo en Colombia en la primera mitad del siglo XX”. En: Revista Estudios Socio-Jurídicos, Vol. 12, núm. 1, pp. 73-97. 
Procesos de construcción de ciudad y vivienda informal. El caso de las barriadas informales de los cerros orientales de Bogotá, Colombia

JARAMILLO, Samuel (1992) La vivienda en Bogotá: evolución de las condiciones habitacionales y de la estructura de producción de vivienda. Documento CEDE N. ${ }^{\circ} 87$, CEDE-Uniandes, Bogotá.

MARTÍNEZ, Alberto (1987). "La Policía de la pobreza”. En: Revista Foro por Colombia, No 3. Bogotá.

MEJÍA, Germán (2000). Los años del cambio: historia urbana de Bogotá, 1820-1910. Universidad Javeriana - Instituto Colombiano de Antropología e Historia, 2. ${ }^{a}$ edición, Bogotá.

MOLANO, Pedro (1997). "San Martín de Porres, barrio popular de Chapinero". En: Bogotá, historia común. Ganadores del concurso de historias barriales y veredales. Alcaldía Mayor de Santa Fe de Bogotá - Departamento Administrativo de Acción Comunal Distrital, Bogotá.

RODRÍGUEZ, Ángela (2014). "Problemática de higiene y hacinamiento en Bogotá a finales del siglo XIX e inicios del siglo XX y primer barrio para obreros". En: Memoria y sociedad, 18, (36), pp. 49-64.

SALDARRIAGA, Alberto (1995) Medio siglo de vivienda social en Colombia 19391989. INURBE, Bogotá.

SERNA, Adrián y GÓMEZ, Diana (2011) Estado, mercado y construcción de ciudad. Una historia social de los conflictos vecinales en la cuenca del río del Arzobispo, Bogotá 1885-2000. Archivo de Bogotá y Universidad Distrital Francisco José de Caldas, Bogotá. SOCIEDAD DE MEJORAS Y ORNATO DE BOGOTÁ (SMOB) (1993). "Plan de ordenamiento físico para la Zona Oriental. Avenida Circunvalar entre las Quebradas El Arzobispo y La Vieja". Alcaldía Local de Chapinero, Bogotá.

TORRES, Carlos; IAKIMOVA, Donka; RINCÓN, John (2009). “¿Es posible pasar de la ciudad informal a la ciudad formal? Aproximación a algunos problemas urbanos y a las estrategias de intervención estatal desde la perspectiva del mejoramiento integral de barrios". En: Procesos urbanos informales y territorio. Ensayos en torno a la construcción de sociedad, territorio y ciudad. Universidad Nacional de Colombia, Bogotá.

TORRES, Carlos (2011) Ciudad informal colombiana. Barrios construidos por la gente. Universidad Nacional de Colombia, Bogotá.

TORRES, Carlos (2012). "Legalización de barrios: acción de mejora o mecanismo de viabilización fiscal de la ciudad dual". En: Bulletin de l'institut français d'études andines, 41 (3), pp. 441-471.

ZAMBRANO, Fabio, ROBERTO, Fabio (2007) Historia de Bogotá: Siglo XX. Villegas Editores, Bogotá. 


\section{Material de archivo consultado}

Alcaldía Mayor de Bogotá (AMB). Sistema Digital de Normas Jurídicas.

Archivo de Planeación Distrital (APD), Bogotá, Colombia. Carpeta Barrio Pardo Rubio. Archivo de Planeación Distrital (APD), Bogotá, Colombia. Carpeta Barrio San Martín de Porres.

Archivo de Planeación Distrital (APD), Bogotá, Colombia. Carpeta Barrio El Paraíso. Archivo de Planeación Distrital (APD), Bogotá, Colombia. Carpeta Barrio Mariscal Sucre. Hemeroteca - Biblioteca Luis Ángel Arango, Bogotá, Colombia. Registro Municipal de Bogotá (RM).

Hemeroteca - Biblioteca Luis Ángel Arango, Bogotá, Colombia. Anuario Municipal de Estadística (AME). 